\section{Johann Wolfgang von Goethe: arte e natureza, poesia e ciência}

\section{Johann Wolfgang von Goethe: art and nature, poetry and science}

Izabela Maria Furtado Kestler

Professora do Departamento de Letras Anglo-Germânicas

Faculdade de Letras - Universidade Federal do Rio de Janeiro

Av. Brigadeiro Trompowski, s/n Cidade Universitária

21941-590 Rio de Janeiro - RJ - Brasil

izabela@alternex.com.br
KESTLER, I. M. F.: Johann Wolfgang von Goethe: arte e natureza, poesia e ciência. História, Ciências, Saúde -Manguinhos, v. 13 (suplemento), p. 39-54, outubro 2006.

Este artigo apresenta a obra científica do poeta alemão Johann Wolfgang von Goethe (1749-1832), a qual engloba os campos da anatomia humana e animal, ótica, geologia, mineralogia, química, botânica, morfologia e meteorologia. Goethe considerava que na natureza e na arte vigiam as mesmas leis, conceituadas por ele como leis da polaridade e da intensificação. Sua obra poética só pode ser avaliada e interpretada à luz de sua visão da harmonia entre homem e natureza, assim como da complementaridade entre espírito e matéria.

PALAVRAS-CHAVE: ciências da natureza; panteísmo; iluminismo; poesia.

KESTLER, I. M. F.: Johann Wolfgang von Goethe: art and nature, poetry and science. História, Ciências, Saúde-Manguinhos, v. 13 (supplement), p. 39-54, October 2006.

The scientific work of German poet Johann Wolfgang von Goethe (1749-1832) encompassed the fields of human and animal anatomy, optics, geology, mineralogy, chemistry, botany, morphology, and meteorology. Goethe believed that nature and art were governed by the same laws, concepts he designated as the laws of "polarity" and "intensification." His poetic works can only be evaluated and interpreted if approached from his understanding of harmony between man and nature, and his view of the complementary relations between spirit and matter.

KEYWORDS: natural sciences; pantheism; enlightenment; poetry. 
Quanto a mim, não posso, dadas as tendências variadas do meu espírito, contentar-me com uma única maneira de pensar. Como poeta e artista sou politeísta, como naturalista, inversamente, sou panteísta, e uma coisa tão decididamente como a outra. Se eu tiver necessidade de um Deus para uma personalidade de ser moral, está tudo preparado para responder também a essa exigência. As coisas do Céu e da Terra são um domínio tão vasto que unicamente os órgãos de todos os seres reunidos são aptos para as envolver.

(Carta de Goethe a Friedrich Heinrich Jacobi, 6 de janeiro de $1813,1998 f)$

$\mathrm{J}$ ohann Wolfgang von Goethe (1749-1832) foi um dos maiores poetas da língua alemã. Muitos o consideram o mais importante autor alemão de todas as épocas. Neste artigo pretendo apresentar uma das facetas mais significativas da obra desse autor: suas pesquisas exaustivas sobre temas científicos, publicadas em várias obras. Aliás, Goethe considerava sua obra científica muito mais importante e relevante do que sua obra poética:

Poetas excelentes conviveram comigo, existiram poetas melhores do que eu e existirão outros muito melhores. A única coisa, da qual me orgulho, é de ter sido neste século o único que compreendeu bem esta ciência difícil da doutrina das cores, sendo assim me sinto superior a muitos outros. (Eckermann, 1999, p. 328, minha tradução)

Nessa passagem de suas Conversas com Eckermann, Goethe referese à obra Zur Farbenlehre (Para uma doutrina das cores), que ele considerava sua obra científica mais importante. Antes, no entanto, de nos determos nessa e em outras obras científicas de sua autoria, pretendo tentar esclarecer como e por que Goethe, autor de obras consideradas clássicas da literatura mundial, como os dramas Fausto I e Fausto II, dedicou tantos anos e tanto empenho aos mais variados temas científicos. Estamos todos acostumados à fragmentação dos saberes, à compartimentalização das especialidades e, sobretudo, à separação rígida entre poesia e ciência, confirmando o diagnóstico feito por Friedrich Schiller (1759-1805) - um desses poetas excelentes aos quais Goethe se refere na citação anterior e seu companheiro de jornada poética durante dez anos - em sua obra A educação estética do homem numa série de cartas, de 1795:

Eternamente acorrentado a um pequeno fragmento do todo, o homem só pode tornar-se fragmento; ouvindo eternamente o ruído monótono da roda que ele aciona, não desenvolve a harmonia do seu ser e, em lugar de imprimir a humanidade em sua natureza, 
torna-se mera reprodução de sua ocupação, de sua ciência. Mesmo esta participação parca e fragmentária, porém, que une ainda os membros isolados ao todo, não depende de formas que eles dão espontaneamente ... mas é-lhes prescrita com severidade escrupulosa num formulário ao qual se mantém preso o livre conhecimento. A letra morta substitui o entendimento vivo, a memória bem treinada é guia mais seguro que gênio e sensibilidade. (Schiller, 1995, p. 41)

Neste sentido, parece a muitos hoje estranho, incomum, e pareceu também muito estranho a seus contemporâneos que um poeta como Goethe se dedicasse tanto a temas considerados não-poéticos, que se recusasse a viver a fragmentação e a especialização de saberes e atividades, que já se tornavam patentes em sua época, e que não conseguisse enxergar a arte e a natureza em mundos e esferas separados. É desse peculiar estranhamento e desconcerto em relação à obra científica de Goethe que vamos tratar também.

\section{Goethe e sua época}

O século XVIII é conhecido como época do Iluminismo ou Esclarecimento, já que é a partir de então que se assentam as bases das investigações nas mais variadas áreas científicas. É a época em que as disciplinas científicas mais diversas - sobretudo as ciências da natureza - começam a se distanciar da metafísica e da teologia. $\mathrm{O}$ impulso filosófico para o estabelecimento dessas disciplinas científicas é indubitavelmente o Iluminismo, ou seja, o ideal da razão. Mas o Iluminismo não constitui um todo homogêneo. Em seu bojo conviviam tendências empiristas, racionalistas, materialistas, idealistas e até as herméticas, fundamentadas em especulações religiosas dos mais variados tipos. Não cabe aqui adentrar esse terreno, mas é interessante observar que, à época de Goethe, havia duas importantes tendências na investigação dos fenômenos da natureza em relação à crença religiosa numa criação divina: a emanentista e a imanentista. Ambas buscavam entender - cada uma com bases filosóficas e teológicas diferentes - a criação do mundo e da natureza e a permanência e evolução da criação. A primeira grosso modo partia do princípio de que o mundo como um todo seria um reflexo, uma emanação ou uma espécie de assinatura de Deus. Seus fundamentos religiosos eram a antiga escola hermética, a seita de Iluminados rosacruzes e os estudos da Cabala. Já para os imanentistas o mundo é por si divino na total autonomia de suas leis e não depende de nenhum todo prototípico.

As leis deste mundo autônomo não são prescritas e garantidas mais por nenhuma revelação divina. Elas resultam da atitude investigativa voltada para a harmonia dos fenômenos, ou seja, 
para o funcionamento como um todo da natureza, para as condições de atividade vital de uma ordem eternamente existente. (Zimmermann, 1974, p. 342, minha tradução).

As bases filosóficas dessa visão imanentista encontram-se sobretudo na filosofia de Baruch de Spinoza e de Giordano Bruno, e remontam também às concepções de natureza dos filósofos gregos estóicos. É dentro desta última concepção que se inserem as idéias científicas de Goethe (Zimmermann, 1974, p. 346).

\section{Estudos científicos}

Em seus tempos de estudante de direito em Leipzig (1765-1768), o jovem Goethe, em contato com os estudantes de medicina, passa a se interessar também pelas investigações científicas mais recentes: a análise das plantas de Carl von Linné (Lineu), a história da natureza do Conde de Buffon e os estudos sobre fisiologia de Albrecht von Haller. Tais investigações se tornarão a base do interesse científico de Goethe da segunda metade do século XVIII. A seguir, durante um período de doença e lenta convalescença na casa dos pais em Frankfurt, Goethe busca apreender os mistérios do mundo e se volta para os estudos alquímicos e herméticos. Ainda que Goethe tenha nos anos seguintes se afastado desse tipo de investigação, restou-lhe desse mergulhar em tratados herméticos a convicção de que a vida é a principal qualidade da natureza. Nos anos posteriores, ainda como estudante, agora em Estrasburgo, Goethe assiste constantemente a aulas de anatomia, medicina e química.

Esses dados da biografia de Goethe ilustram a amplitude de seus interesses, sua curiosidade insaciável e, sobretudo, um aspecto fundamental de sua personalidade: o querer saber tudo. Até o fim de sua longa vida, Goethe não só pesquisa em vários campos de conhecimento, como também se corresponde com os mais influentes cientistas de seu tempo. É importante assinalar, nesse contexto, a amizade e a correspondência de Goethe com o botânico Karl Friedrich Phillipp von Martius (1794-1868), que veio ao Brasil liderando a comitiva austro-bávara de cientistas e acompanhou a

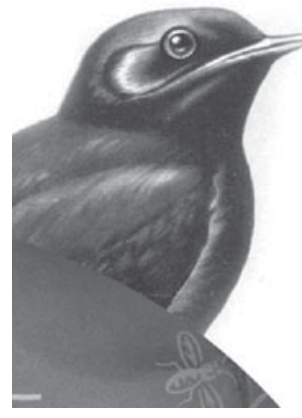
arquiduquesa austríaca Leopoldina, noiva do príncipe D. Pedro de Alcântara. Martius e o zoólogo Johann Baptiste von Spix realizam uma expedição científica do Rio de Janeiro à Amazônia, de 1817 a 1820. Um dos resultados dessa expedição foi a publicação dos três volumes da obra Viagem pelo Brasil em 1823, 1828 e 1831 (Sousa, 2000 , p. 40). Goethe não só se correspondeu com Martius, mas também o encontrou várias vezes após o retorno deste à Alemanha. Martius chegou a lhe enviar também amostras do material recolhido durante a expedição. Outro interlocutor de Goethe foi o renomado naturalista Alexander von Humboldt (1769-1859), que embora não 
tenha estado no Brasil, conheceu e pesquisou toda a parte norte da região amazônica.

A pesquisa sistemática dos supracitados campos das ciências da natureza, no entanto, só vai acontecer a partir da mudança de Goethe para o grão-ducado de Weimar, em 1775. Não cabe aqui descrever em detalhes quais eram suas funções na corte e quais os cargos por ele exercidos. É importante, no entanto, assinalar que Goethe gozava da confiança irrestrita do grão-duque Carl August e que, como conselheiro-secreto, recebia o segundo salário mais alto do funcionalismo no Grão-Ducado. Neste ponto, é necessário lembrar que a Alemanha era na época uma quimera, um sonho ainda não realizado. Não existia a Alemanha, e sim vários reinos, ducados, cidades-Estados, grão-ducados etc. A primeira unificação da Alemanha só iria se realizar em 1871, muito tempo depois da morte de Goethe. Em Weimar, onde passou a exercer atividades políticas e administrativas, como por exemplo a reativação das minas de Ilmenau, Goethe passou a estudar com mais empenho as áreas da mineralogia e da geologia. Nesses campos publicou vários estudos, dos quais o mais significativo é Über den Granit (Sobre o granito), de 1784, concebido como parte de um romance que teria o título Über das Weltall (Sobre o cosmo), o qual não foi executado. Para Goethe, o granito era a pedra primordial (Urgestein), que não poderia ser abalada nem por terremotos nem por catástrofes vulcânicas. O granito seria, portanto, o fundamento da Terra. Nos estudos mineralógicos e geológicos, interessava a Goethe também fazer o levantamento sistemático das ocorrências minerais no grão-ducado para uma futura exploração dessas riquezas.

Em 1804 Goethe foi eleito presidente da Sociedade Mineralógica de Jena, fundada em 1798. Na área da geologia, interessava-se sobretudo pelos estudos que buscavam esclarecer a evolução geológica da Terra. À época de Goethe, acreditava-se ainda na cronologia mosaica, ou seja, datava-se a idade da Terra a partir dos registros dos patriarcas, de Adão até Noé, os quais apontavam a criação do planeta no ano de 4004 a.C. Somando-se 4.004 aos 1.800 anos após o nascimento de Cristo, chegava-se então à data de mais ou menos 6 mil anos de idade (Göres, 1981, p. 182). Acreditava-se, portanto, na ocorrência de um dilúvio universal, tal como descrito na Bíblia. Havia à época duas tendências conflitantes no campo do estudo da evolução geológica da Terra: a primeira, a dos vulcanistas (alusão ao deus greco-romano Vulcão), que considerava a incidência de terremotos e erupções vulcânicas como as forças naturais que teriam moldado e continuariam moldando a evolução da Terra; a segunda, a dos netunistas (numa alusão ao deus dos mares Netuno da mitologia greco-romana), defendia a idéia de uma evolução bem menos conturbada. Ou seja, pressupondo o dilúvio, a Terra em seu estado atual teria sido formada por camadas que teriam 
se sedimentado umas sobre as outras. Goethe era adepto desta teoria do netunismo.

É importante aqui assinalar que a adesão de Goethe a essa teoria se insere no contexto mais amplo de sua visão de mundo, de suas idéias sociais e antropológicas. Não é por acaso que ele adota uma visão da história da formação da Terra que privilegia o aspecto evolutivo pacífico e não catastrófico. Erupções vulcânicas e terremotos são para ele análogos às transformações sociais violentas, revolucionárias. Lembremo-nos aqui que Goethe foi contemporâneo da Revolução Francesa, a qual ele nunca aprovou e cujas conseqüências ele deplorava. Há inúmeras passagens em sua obra dramática e lírica posteriores à eclosão da Revolução que atestam seu temor em relação às irrupções de camadas sociais inferiores, vistas como erupções do magma vulcânico com alto poder de destruição. Dentro de sua concepção de mundo, existiria uma conexão entre a evolução da Terra e a evolução do homem, ou melhor, entre a história da Terra e a história humana.

Em seu relato autobiográfico da estada de quase dois anos na Itália, de 1786 a 1788, Viagem à Itália, Goethe descreve com horror uma erupção vulcânica na Sicília assim como, analogamente, os traços bárbaros do carnaval em Roma. A erupção do magma vulcânico e a 'erupção' de camadas inferiores irracionais são o contraponto nessa obra à construção e revitalização do paradigma clássico da forma perfeita e da beleza centrada no equilíbrio entre o espírito e a matéria. Goethe buscará moldar sua obra literária posterior ao retorno da Itália segundo esse paradigma clássico, vinculado estreitamente à Antiguidade clássica grega.

É sob influência de seu amigo e filósofo dos anos de estudo em Estrasburgo, Johann Gottfried Herder, que Goethe empreende, no início da década de 1780, seus estudos nos campos da anatomia humana, mais especificamente da osteologia e da zoologia. Partia do princípio da existência de um parentesco estreito entre o homem e os animais, parentesco este negado veementemente pelos teólogos e filósofos da época, como Kant, por exemplo. Goethe então descobre o osso intermaxilar no homem, que todos os animais vertebrados possuem, cuja existência sempre fora negada pelos anatomistas de então. A inexistência deste osso seria - segundo esses anatomistas, influenciados pelas correntes teológicas predominantes - o estigma da diferença entre os homens e os animais, $\mathrm{o}$ marco que distingue a bestialidade, a irracionalidade animal da racionalidade humana. Para Goethe, "o homem é o parente mais próximo dos animais", e no aspecto físico "somente um matiz de uma harmonia maior" (Carta de Goethe a Karl Ludwig von Knebel de 17 de novembro de 1784,1998f). Além disso, Goethe estava convencido de que "a natureza em sua infinita variedade ... parece ter criado todos os seres vivos segundo um único modelo fundamental de 
organização" (Carta de Goethe a Karl Ludwig von Knebel de 17 de novembro de 1784, 1998f):

O homem como elemento de uma corrente de fenômenos da natureza, a idéia do parentesco universal genético e morfológico de todos os seres orgânicos: isto parece já apontar para a teoria da evolução de Darwin, e efetivamente este mesmo e Ernst Haeckel consideravam Goethe um precursor da teoria da evolução... (Borchmeyer, 1994, p. 119, minha tradução)

Goethe chegou a essas idéias evolutivas, como já mencionado, por influência da obra filosófico-antropológica de seu amigo, Johann Gottfried Herder (1744-1803), mais especificamente de uma das obras deste: Ideen zur Philosophie der Geschichte der Menschheit (Idéias para uma filosofia da história da humanidade), publicada em quatro partes entre 1784 e 1791.

É essa idéia de um modelo fundamental, ou seja, de uma continuidade entre a história natural e a história humana, que também vai inspirar seus estudos no campo da botânica, iniciados quando ele começa a plantar um jardim no terreno adjacente a sua casa em Weimar. A partir da nomenclatura estabelecida por Carl von Linné (Lineu) em sua Fundamenta botanica, e em contraposição a ela, Goethe procura entender o reino vegetal segundo outro sistema, ou seja, em vez de buscar as diferenças exteriores entre as plantas e assim classificá-las, ele busca encontrar na multiplicidade, na variedade das formas vegetais uma forma primordial, uma forma típica. Além disso, interessa-lhe explicar quais são as leis que determinam as variações, as evoluções a partir dessa forma primordial. Em outras palavras, ele busca de um lado a Urpflanze (planta primordial, originária) e as leis da Metamorphose (metamorfose) das plantas. É durante a já mencionada estada na Itália que Goethe passa a literalmente buscar entre a multiplicidade de plantas para ele até então desconhecidas a sua quimera particular: a Urpflanze. A idéia da metamorfose também lhe ocorre nessa época.

É uma verdadeira infelicidade ser perseguido e tentado por toda sorte de espíritos. Hoje, de manhã cedo, ia eu para o jardim público com o firme e tranqüilo propósito de prosseguir os meus sonhos poéticos, só que, antes que desse por isso, um outro fantasma, que por estes dias já me tinha seguido furtivamente, me apanhou. As muitas plantas que, outrora, eu estava habituado a ver apenas em cubas e potes e, mesmo a maior parte do ano, só através de estufas, estão aqui belas e frescas ao ar livre e, ao cumprirem sua função de modo perfeito, tornam-se para nós mais eloqüentes. Perante tantas formações novas e variadas, veio-me a antiga mania de saber se entre esta multidão não podia descobrir a planta originária [Urpflanze]. Ora, uma planta assim tem que existir! Como poderia reconhecer que esta ou aquela formação é 
uma planta, se não tivessem sido todas formadas de acordo com um modelo? (Goethe, Palermo, 17 de abril de 1787, 1998b, p. 266 )

A metamorfose é para Goethe sinônimo da transição entre as formas que as plantas vão adquirindo durante seu crescimento, ou seja, as leis pelas quais a planta produz uma parte "através da outra e apresenta as partes mais diferentes pela modificação de um único órgão" (Goethe, 1993, p. 64).

Essa primeira investigação botânica foi publicada em 1790 sob o título de Versuch die Metamorphose der Pflanzen zu erklären (Tentativa de explicação da metamorfose das plantas). É importante assinalar aqui que a paixão pela botânica acompanha Goethe por toda a vida. Seu interesse por este campo do saber causou desde o início estranheza a seus contemporâneos. Seu editor na época se recusou a publicar o estudo sobre a metamorfose e ele teve de recorrer a outra empresa. Mas é aqui, no estudo da botânica, nas investigações anteriores sobre a anatomia, a geologia e a zoologia, e posteriormente na investigação sobre a luz e as cores em sua Farbenlehre, que vai se revelando e delineando o propósito de Goethe de tentar apreender o processo formativo da natureza viva como modelo de qualquer forma artística. É no momento em que tem a intuição da Urpflanze que Goethe indica uma "confluência entre a arte e seu modo de representar a natureza" (Molder, 1993, p. 26). Ou seja, para ele existe uma identidade, um paralelismo entre as leis da natureza e as leis da arte. Neste aspecto, Goethe segue, segundo suas próprias palavras, as idéias do filósofo Immanuel Kant, sobretudo aquelas expostas em sua Kritik der Urteilskraft (Crítica do juízo) de 1790:

as grandes idéias principais da obra eram análogas à minha criação, ao meu fazer e pensar; a vida interior da arte assim como da natureza, seu agir recíproco a partir do interior eram abordados expressamente no livro. Os produtos destes dois mundos infinitos deveriam existir por si e para si mesmos... (Goethe, 1998a, p. 28, minha tradução)

Ou seja, nem a arte nem a natureza têm uma finalidade, um objetivo; os produtos da arte e da natureza são e existem independentemente da finalidade que os homens impõem a eles.

A partir do estudo da botânica, Goethe vai adentrar o campo da morfologia (estudo das formas que a matéria pode tomar), ciência, aliás, batizada por ele, que se ocupa com a forma, a formação e a transformação dos seres. Suas idéias sobre isto estão expostas no texto Zur Morphologie (Sobre a morfologia), de 1817. Cito, aqui, uma passagem longa desse texto, que esclarece a maneira como Goethe procede em suas pesquisas e quais são seus objetivos científicos: 


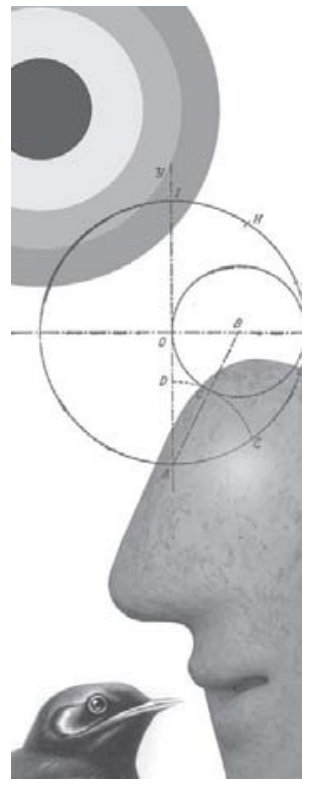

Quando nós nos apercebemos dos objetos naturais e sobretudo dos objetos vivos de modo que desejamos proporcionar uma compreensão do conjunto do seu ser e da sua atividade, cremos chegar da melhor maneira a um tal conhecimento, através da dissociação das partes; e este caminho é, com efeito, próprio para nos levar bem longe. Que nos seja permitido lembrar em poucas palavras aos amigos da ciência o modo como a química e a anatomia contribuíram para a compreensão e a visão de conjunto da Natureza. Constantemente prosseguidos, porém, estes esforços de dissociação produzem também muitos inconvenientes. $\mathrm{O}$ ser vivo pode ser decomposto nos seus elementos, mas a partir deles não se pode reconstituí-lo e devolver-lhe a vida. Isto é verdadeiro já para muitos corpos inorgânicos, e com maior razão para os orgânicos. É por isso que em todas as épocas também se manifestou no homem de ciência um impulso para reconhecer as formações vivas enquanto tais, de apreender as suas partes exteriores tangíveis e visíveis, para as aceitar como indícios e, assim, dominar de certo modo o todo na intuição. Não é preciso expor muito minuciosamente quanto este desejo científico está ligado ao impulso artístico e ao impulso de imitação. Encontramos, por conseguinte, no curso da arte, do saber e da ciência, várias tentativas para fundar e desenvolver uma doutrina, a que gostaríamos de chamar Morfologia ... O alemão tem para o conjunto da existência de um ser real a palavra 'forma' (Gestalt). Com este termo ele abstrai do que está em movimento, admite que uma coisa consistente nos seus elementos seja identificada, fechada e fixada no seu caráter. Mas, se considerarmos todas as formas, em particular as orgânicas, descobrimos que não existe nenhuma coisa subsistente, nenhuma coisa parada, nenhuma coisa acabada, antes que tudo oscila num movimento incessante. A nossa língua costuma servirse, e com razão, da palavra 'formação' (Bildung) para designar tanto o que é produzido como o que está em vias de o ser. Portanto, se quisermos introduzir uma Morfologia, não devemos falar de forma; se, pelo contrário, usarmos a palavra, então temos de tomála em qualquer dos casos apenas como idéia ... O que está formado, transforma-se de novo imediatamente e nós temos, se quisermos de algum modo chegar à intuição viva da Natureza, de nos mantermos tão móveis e plásticos como o exemplo que ela nos propõe ... Cada ser vivo não é uma coisa singular, mas uma pluralidade; mesmo no caso em que nos aparece como indivíduo, persiste, contudo, como uma coleção de seres vivos autónomos, que, segundo a idéia, segundo a disposição, são iguais, mas quando se manifestam podem ser iguais ou semelhantes, desiguais ou dissemelhantes. Estes seres estão em parte originariamente já unidos, em parte encontram-se e reúnem-se. Separam-se e procuram-se de novo e provocam assim uma produção infinita de todas as maneiras e em todas as direções. (Goethe, 1998g, p. 55-6)

São essas idéias em torno da morfologia, que apontam na multiplicidade das formas para a unidade de tudo o que é vivo, 
real, que nortearam os estudos de Goethe nas áreas de botânica, zoologia e osteologia. A noção da mobilidade entre as formas, da transição de uma para outra, encontra-se na idéia de metamorfose, ou melhor, citando Goethe: "A forma é algo em movimento, algo que advém, algo que está em transição. A doutrina da forma é doutrina da transformação. A doutrina da metamorfose é a chave de todos os sinais da natureza" (Goethe, 1957, p. 128).

É também durante sua estada na Itália que Goethe se debruça sobre a questão das cores, quando se dá conta de que os pintores não estudam as combinações de cores para compor seus quadros, ou seja, a utilização das cores não parece seguir segundo Goethe nenhum método. (Goethe, 1998b, p. 526). Mas é quando observa a luz através do prisma do conselheiro Büttner em janeiro de 1790, já de volta a Weimar, que Goethe chega à falsa conclusão de que Newton estaria errado. Começa aí a pesquisa sistemática e exaustiva a partir de uma conclusão falsa, que no correr dos anos se tornou não só uma polêmica acirrada contra as idéias de Newton e a de seus discípulos como também uma questão de fé. A luz, que para Goethe é o símbolo do princípio único e divino, tinha de ser defendida contra aqueles que a decompunham.

Em sua obra Farbenlehre (A doutrina das cores), de 1810, a mais abrangente de suas obras, publicada em dois volumes, Goethe finalmente apresentou suas idéias sobre as cores. No campo dos fenômenos óticos, o Urphänomen (proto-fenômeno, fenômeno original) é o antagonismo fundamental entre a luz e a treva, que é mediado pelo elemento Trübe (opaco, turvo). A tese básica de Goethe é de que as cores não são elementos da luz, mas sim que surgem através do antagonismo e cooperação da luz e da treva, e da mistura do claro e do escuro. Mas como a mistura do claro e do escuro resulta na cor cinza, as cores só surgiriam na transição da luz por um meio opaco, como por exemplo na passagem dos raios de sol pela atmosfera enevoada (Borchmeyer, 1994, p. 199). As cores básicas de Goethe são três: amarelo, azul (cores primordiais) e o vermelho, que contém dinamicamente todas as cores. Além disso, Goethe distingue três tipos de cores: as cores fisiológicas, que pertencem ao olho humano, as cores físicas, observáveis com a ajuda de ou em meios opacos, e as cores químicas, pertencentes aos objetos. Interessante é também assinalar que Goethe apresenta nessa obra também uma teoria sobre os efeitos de cada cor e da combinação de cores sobre o ânimo e o espírito humano. Assim, por exemplo, a cor azul, que carrega em si a escuridão, posto que deriva da cor negra, nos transmite o sentimento de frieza e vazio (Goethe, 1998c, p. 498). Não cabe aqui detalhar todas as características desses três tipos de cores nem explicitar todos os passos que Goethe deu para chegar tais resultados. Goethe fundamenta toda a sua doutrina a partir da idéia de que as cores acontecem, surgem na relação que se estabelece entre o olho e a luz. 
O olho deve sua existência à luz. A partir de órgãos biológicos indiferentes, a luz cria um órgão, que se igualaria a ela, e assim o olho se forma na luz e para a luz, para que a luz interior vá ao encontro da exterior. Aqui nos lembramos da antiga escola jônica, a qual repetia sempre que o semelhante só é reconhecido pelo semelhante, assim como das palavras de um antigo místico, as quais nós recitamos aqui da seguinte forma: Se o olho não fosse solar,/ como ele poderia enxergar a luz?/ Se a força própria de Deus não vivesse em nós/ Como poderia o divino nos maravilhar? Ninguém pode negar aquele parentesco imediato da luz e do olho; mas concebê-los como sendo uma só e mesma coisa pode causar estranheza. No entanto, torna-se perceptível, quando se afirma que no olho mora uma luz em repouso, que é estimulada por dentro e por fora ao menor motivo. Na escuridão podemos evocar através da imaginação as imagens mais brilhantes. No sonho os objetos nos surgem como no dia claro ... A cor é a natureza obrigatória em relação ao sentido da visão. (Goethe, 1998c, p. 324)

Além disso, a doutrina das cores e também a metamorfose das plantas são determinadas pelas leis da polaridade (Polarität) e da intensificação (Steigerung), conceitos fundamentais de sua visão de mundo como um todo, da natureza, da vida humana e da arte. $\mathrm{O}$ conceito de polaridade pertence à matéria, e o da intensificação ao espírito, pensados conjuntamente.

As duas grandes forças motoras de toda natureza: o conceito de polaridade e de intensificação, aquela da matéria, pertencente à matéria, esta ao contrário ao espírito, desde que a pensemos espiritualmente; aquela [a polaridade] é e está numa perene atração e repulsão, esta [a intensificação] existe e está num perene ascender. Mas porque a matéria nunca existe sem espírito, o espírito nunca existe e não pode ser efetivo sem a matéria, assim a matéria também tem a capacidade de se elevar, de ascender, assim como o espírito não pode deixar de atrair e de repelir; assim só tem a capacidade de pensar aquele que dividiu suficientemente para poder unir e que uniu suficientemente para de novo poder separar. (Goethe, 1998d, p. 48)

Enquanto compreensão de toda natureza, como podemos entender e exemplificar essas leis da polaridade e da intensificação?

Na mundividência goetheana, os contrários não constituem dualidades antagônicas, mas, sim, unidades polares. Luz e treva, dia e noite, vida e morte são o anverso e o reverso de uma mesma unidade polarizada ... A luz existe, porque coexiste com a treva ... A vida não subsiste, senão porque a morte existe. Céu e terra, homem e mulher, masculino e feminino são parelhas requeridas pela procriação. Separar significa engendrar ... A polarização do ilumínio e da sombra produz a cor. A propriedade fundamental 
da unidade polarizada, que preside à gênese e ao desenvolvimento da vida em geral, consiste em dividir o unido e, ao mesmo tempo, unir o dividido ... A vida da natureza é a eterna sístole e diástole... (Melo e Souza, 1998, p. 22)

Além disso, "a intensificação está ligada diretamente à idéia de metamorfose. Esta significa um progredir para a perfeição" (Wankmüller, 1998, p. 633, minha tradução). E na medida em que o espírito, que é contrário à matéria, constitui com esta dois pólos de uma mesma unidade, o que é espírito na matéria tende à ascensão, à intensificação, e o que é matéria no espírito persegue a objetivação, a exteriorização.

Polaridade e intensificação são ambos duplos em movimento. Se a polaridade é característica da matéria, e se o espírito e a matéria são também uma polaridade, então o espírito tem sua origem na matéria. Mas se a intensificação é o modo do movimento espiritual, então este processo também é uma ascensão da matéria. Intensificação aí não é auto-alienação, mas sim um tornar-se essência, uma aproximação à essência. (Weizsäcker, 1998, p. 550, minha tradução)

Esta essência, este ser, que é eterno, manifesta-se, está presente em todas as suas aparições, e também nas transformações das formas dos seres vivos.

É importante assinalar aqui que se a teoria das cores físicas e químicas na Farbenlehre não pode reivindicar estatuto científico, o mesmo não acontece no caso das cores subjetivas. Ou seja, que o olho humano em face do escuro exija o claro e que o olho em face de cada cor produza sua cor complementar, foi comprovado há algumas décadas pela moderna psicologia da percepção e pela neurofisiologia (Borchmeyer, 1994, p. 201). Nos últimos anos de sua vida, Goethe se dedica também ao estudo da meteorologia, investigando as formações de nuvens. Suas observações encontram-se na obra Versuch einer Witterungslehre (Pesquisando a meteorologia) de 1825.

\section{De que forma se distingue a visão de mundo de Goethe da visão das ciências naturais em geral?}

Aqui não pretendo apresentar os fundamentos das ciências naturais em geral nem levantar questões que meus parcos conhecimentos científicos não poderiam responder. Não quero aqui também nem justificar nem defender a visão de mundo poético-científica de Goethe e nem acusar a prática das ciências de ser única e exclusivamente mecanicista ou unilateral. Seria uma ousadia também misturar ou comparar discursos e códigos diferentes como fazem alguns autores de certas filosofias em moda, que citam sem critério nenhum fórmulas de matemática ou mecânica quântica para tornar 
supostamente mais científicos seus textos filosóficos, psicanalíticos ou literários. Refiro-me aqui às imposturas denunciadas por dois físicos nas obras de Jacques Lacan, Jean Baudrillard e outros (Sokal \& Bricmont, 1997). Não ousaria também afirmar, como fez o professor de literatura alemã Fred Amrine num simpósio promovido em Weimar em 1998, tratando da obra A doutrina das cores, que o paradigma científico proposto por Goethe oferece a única alternativa moderna e metodologicamente consistente aos paradigmas científicos dominantes (Amrine, 1998, p. 37). Quero aqui tão-somente assinalar as diferenças fundamentais, abordadas por vários especialistas da obra científica de Goethe, entre sua visão científica e a da ciência moderna. Segundo o físico Carl Friedrich von Weizsäcker, o modo de pensar das ciências da natureza a partir do século XVI, sua consciência científica foi desenvolvida por nomes como Kepler, Copérnico, Galileu e Newton. Este modo de pensar não é mais metafísico e sim metódico.

Para a ciência contemporânea é suficiente que o pesquisador tenha feito experimentos e que qualquer um possa repeti-lo. O decisivo não é o próprio ato da experiência, mas sim a exposição dos fatos ... E os fatos por si sós são importantes não como caso singular, mas sim como tipo ... A experiência pode ser repetida. Aquilo que pode ser repetido é no entanto substituível. A experiência dos sentidos, na qual se baseia a ciência de Goethe, é insubstituível. (Weizsäcker, 1998, p. 540, minha tradução)

Além disso, enquanto a ciência procura extrair dos experimentos científicos leis aplicáveis a uma determinada gama de fenômenos, Goethe busca apreender a forma, capturar a transição de uma forma para outra, tecer analogias entre fenômenos no sentido de que só o semelhante pode entender o semelhante, intuir nos fenômenos as leis da polaridade e da intensificação e contemplar desinteressadamente os fenômenos da natureza que o intrigam. A visão científica de Goethe também não compreende a busca das causas e das finalidades e nem dá espaço à abstração matemática. Portanto, as experiências que ele faz não podem ser instrumentalizadas; a intenção de Goethe, na realidade, consiste em estimular seus leitores a realizar também seus próprios experimentos: “Ele não queria nem criar nem superar a natureza. Ele se identificava como criação desta natureza e queria entendê-la e obedecê-la" (ibidem, p. 545). Outro aspecto importante de sua visão científica diz respeito à consciência dos limites que não devem ser ultrapassados pelas experiências científicas. Goethe estava convencido de que o homem não deveria ultrapassar suas fronteiras, seus limites impunemente. Disso resulta sua aversão ao uso de aparelhos científicos, embora tenha possuído uma grande quantidade de instrumentos óticos. Na visão de Goethe, os aparelhos 
falsificam a imagem do mundo que é permitida ao indivíduo e abrem através do deslocamento da perspectiva natural um abismo entre o experimentar e o reconhecer, entre o homem e a natureza ... A experimentação com aparelhos e o conseqüente cálculo matemático não só tentam eliminar o homem completamente como também violentam a natureza. Goethe considera os protofenômenos (Urphänomene) como as formas adequadas de conhecimento e contemplação para os homens. Neles as forças formadoras da natureza tornam-se tangíveis, palpáveis. Em sua ambivalência elas pertencem a um lugar de realidade ideal, onde o elemento e o espírito se encontram ... Nesta mesma localidade está a morada da arte. (Wankmüller, 1998, p. 631, minha tradução)

Ou, nas palavras do próprio Goethe, colhidas por seu secretário Eckermann:

O máximo que o homem pode alcançar ... é o maravilhamento; e se o proto-fenômeno lhe assombra, lhe maravilha, então ele deve ficar satisfeito; algo mais elevado, mais sublime o proto-fenômeno não pode lhe proporcionar, e mais além disso ele não deve procurar; aqui é o limite. (Eckermann, 1999, p. 319, minha tradução)

O abuso indiscriminado da natureza, a destruição do meio ambiente, a instrumentalização do saber científico para os fins da acumulação de capital e muitos dos horrores que vivemos hoje, os quais fazem parte também da história e da prática científica desde seu início, não seriam possíveis dentro do paradigma científico de Goethe (Muschg, 1999, p. 196). Tal paradigma, moldado pela visão da totalidade da natureza e de sua relação com o homem, baseia-se na idéia de uma correlação entre homem e natureza de uma perspectiva panteísta, ou seja, cada ser vivo possui uma essência divina. A obra científica de Goethe é uma cosmogonia poético-científica, na qual homem e natureza, sujeito e objeto, espírito e matéria não estão separados. Aliás, sua obra poética também não pode ser compreendida em sua totalidade sem que se apreenda sua relação íntima com a obra científica.

Embora o fisico Werner Heisenberg tenha advogado em 1955 a idéia de que "a antiga divisão do mundo num decorrer objetivo em espaço e tempo de um lado e a alma de outro lado, na qual este decorrer se reflete, ou seja, a distinção cartesiana entre res cogitans e res extensa, não é mais apropriada como ponto de partida do entendimento da moderna ciência da natureza" (Heisenberg, 1967, p. 5, minha tradução), tal divisão permanece até hoje constitutiva do fazer científico. Goethe pode ter incorrido numa série de erros científicose com certeza foi infeliz em sua polêmica contra os seguidores de Newton, mas ele foi o único cientista da modernidade que conseguiu superar o esquema da distinção cartesiana, porque para ele o espírito está realmente presente na matéria. Além disso, ele foi o único que conseguiu 
pensar ciência e poesia como uma totalidade, o que até hoje desconcerta não só cientistas como também poetas. É nessa unidade entre sujeito e objeto e no desenvolvimento de todas as capacidades humanas que se fundam a intenção da obra poética e da obra científica desse autor. Ou como escreveu o próprio Goethe:

Quem não está convencido de que todas as manifestações da essência humana, a sensibilidade e a razão, a intuição e o entendimento, devem ser desenvolvidas para se tornarem uma decisiva unidade, independentemente de quais destas qualidades se tornem predominantes em cada um, passará a vida se esgotando nesta redução desagradável e nunca compreenderá, porque tem tantos inimigos tenazes e porque ele mesmo às vezes também vai confrontar outros como inimigo. Assim, um homem nascido e formado para as assim chamadas ciências exatas, quando estiver no ápice de sua razão-entendimento, não compreenderá facilmente que pode haver também uma fantasia sensível exata, sem a qual a arte é impensável. (Goethe, 1998e, p. 42)

\section{REFERÊNCIAS BIBLIOGRÁFICAS}

Amrine, Fred

1998

Borchmeyer, Dieter 1994

Eckermann, Johann Peter 1999

Göres, Jörn (org.) 1981

Goethe, Johann Wolfgang von 1999

Goethe, Johann Wolfgang von 1998a

Goethe, Johann Wolfgang von $1998 b$

Goethe, Johann Wolfgang von 1998c

Goethe, Johann Wolfgang von $1998 \mathrm{c}$

Goethe, Johann Wolfgang von $1998 d$
Goethes wissenschaftliche Paradigmen.

Symposium Goethes Farbenlehre. v. II. Weimar: Goethe-Gesellschaft.

Weimarer Klassik.

Weinheim: Beltz Athenäum.

Gespräche mit Goethe in den letzten Jahren seines Lebens.

München: DTV.

Goethes Leben in Bilddokumenten.

München: C. H. Beck'sche Verlagshandlung.

Viagem à Itália 1786-1788. Trad. Sérgio Tellarolli.

São Paulo: Companhia das Letras.

Einwirkung der neueren Philosophie.

In: J. W. Goethe-Werke. München: DTV. v. 13, p. 25-9.

Italienische Reise. In: J. W. Goethe-Werke.

München: DTV. v. 11, p. 7-556.

Farbenlehre. In: I. W. Goethe-Werke.

München: DTV. v. 13, p. 314-523.

Farbenlehre. In: J. W. Goethe-Werke.

München: DTV. v. 14, p. 7-269.

Erläuterung zu dem aphoristischen Aufsatz Die Natur.

In: J. W. Goethe-Werke. München: DTV. v. 13, p. 48-9. 
Goethe, Johann

Wolfgang von

1998e

Goethe, Johann

Wolfgang von $1998 f$

Goethe, Johann

Wolfgang von $1998 \mathrm{~g}$

Goethe, Johann

Wolfgang von 1993

Goethe, Johann

Wolfgang von

1957

Heisenberg, Werner 1967

Melo e Souza, Ronaldes 1998

Molder, Maria Filomena 1995

Molder, Maria Filomena 1993

Muschg, Adolf 1999

Requardt, Manfred 1982

Schiller, Friedrich 1995

Sokal, Alan;

Bricmont, Jean 1997

Sousa, Celeste

Ribeiro de 2000

Wankmüller, Rike 1998

Weizsäcker, Carl

Friedrich von 1998

Zimmermann, Rolf Christian 1974
Ernst Siedenroth, Psychologie zur Erklärung der Seelenerscheinungen. In: J. W. Goethe-Werke. München: DTV. v. 13, p. 41-3.

Briefe, Tagebücher, Gespräche. Ed.: Mathias Bertram. Berlin: Directmedia Publishing. (Digitale Bibliothek; Werke; 10); CD-Rom.

Morphologie. In: J. W.

Goethe-Werke. München: DTV. v. 13, p. 53-250.

A metamorfose das plantas. Trad., introd., notas e apêndice de Maria Filomena Molder. Lisboa: Imprensa Nacional-Casa da Moeda.

Aufsätze, Fragmente, Studien. Zur Morphologie. In: Goethe, Die Schriften zur Naturwissenschaften. Halle: Deutsche Akademie der Naturforscher. v. 10, p. 110-30.

Das Naturbild Goethes und die technisch-naturwissenschaftliche Welt. Jahrbuch der Goethe-Gesellschaft. n. 29. Disponível em: geocities.com/Athens/ 6674/heisenberg.html. Acesso em 13 de agosto de 2006.

A doutrina goetheana da polaridade. Cadernos de Letras, Rio de Janeiro: Faculdade de Letras/UFRJ, n. 13, p. 22-6.

O pensamento morfológico de Goethe.

Lisboa: Imprensa Nacional-Casa da Moeda.

Introdução. In: Goethe, J. W. A metamorfose das plantas. Trad., introd., notas e apêndice de Maria Filomena Molder. Lisboa: Imprensa Nacional-

Casa da Moeda.

Bis an die Sterne weit?

Goethe und die Naturwissenschaften. Frankfurt a. M.: Insel.

Goethe und die 'anschauende Urteilskraft' oder 'Feinsinn' contra 'Geometrie' In: Arnold, Heinz Ludwig (org.) Johann Wolfgang Goethe. Sonderband. München: Edition Text und Kritik. p. 248-65.

A educação estética do homem numa série de cartas. 3. ed. Trad. Roberto Schwarz e Márcio Suzuki. São Paulo: Iluminuras.

Impostures intellectuelles.

Paris: Ed. Odile Jacob.

O Brasil na obra de Goethe. Forum Deutsch-Revista brasileira de estudos germânicos. Rio de Janeiro, v. 4, n. 1, p. 26-44.

Nachwort zur Farbenlehre. In: J. W. Goethe-Werke. München: DTV. v. 13, p. 613-40.

Einige Begriffe aus Goethes Naturwissenschaft.

In: J. W. Goethe-Werke. München: DTV. v. 13, p. 539-55.

Goethes Polaritätsdenken im geistigen Kontext des 18. Jahrhunderts. Jahrbuch der deutschen Schiller Gesellschaft, Stuttgart, v. 1, ano 18, p. 304-47. 